\title{
Total Clearance Observed by Fraction Dose Normalized by Surface Area
}

National Cancer Institute

\section{Source}

National Cancer Institute. Total Clearance Observed by Fraction Dose Normalized by

Surface Area. NCI Thesaurus. Code C92401.

The observed total body clearance for extravascular administration based on the fraction of dose absorbed and divided by the surface area. 